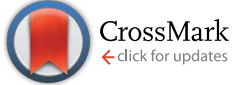

Cite this: RSC Adv., 2017, 7, 16616

Received 8th February 2017

Accepted 28th February 2017

DOI: 10.1039/c7ra01587a

rsc.li/rsc-advances

\section{Incorporating a silicon unit into a polyether backbone-an effective approach to enhance polyether solubility in $\mathrm{CO}_{2} \dagger$}

\begin{abstract}
Yongfei Zhang, Zewen Zhu, Zhenguo Bai, Wei Jiang, Fengqi Liu and Jun Tang*
A series of poly(silyl ether)s were prepared by condensation polymerization and hydrosilation polymerization through incorporating a silicon unit into a polyether backbone. The phase behavior of poly(silyl ether)s in $\mathrm{CO}_{2}$ was measured in terms of concentration, molecular weight and temperature. Through incorporating the silicon unit, the poly(silyl ether)s exhibited high solubility in $\mathrm{CO}_{2}$ compared to the precursors of polyether. For example, the cloud point pressure decreased from $24.6 \mathrm{MPa}$ for poly(1,2-propene glycol) (PPG) to $16.5 \mathrm{MPa}$ for poly(dimethylsiloxane-alt-propene glycol) (PSPG) with a concentration of $0.6 \mathrm{wt} \%$ at $30^{\circ} \mathrm{C}$. Moreover, the molecular weight dependence of solubility for PSPG and PSDPG in $\mathrm{CO}_{2}$ compared with PPG was weakened. The key factor to enhance the solubility of poly(silyl ether)s in $\mathrm{CO}_{2}$ was systematically researched via surface tension and glass transition temperature. The results demonstrated that higher solubility of synthesized poly(silyl ether)s in $\mathrm{CO}_{2}$ compared to PPG was mainly attributed to lower polymer-polymer interactions.
\end{abstract}

\section{Introduction}

Due to the characteristics of green, safety and controllable solvent power, liquid and supercritical $\mathrm{CO}_{2}$ is considered to be an attractive substitute for hazardous organic solvents in polymer syntheses. ${ }^{\mathbf{1}, \mathbf{2}}$ However, its feeble solvation ability for polar and high molecular weight materials bring several difficulties for its wide practical applications. ${ }^{3-6}$ To address this limitation, the use of " $\mathrm{CO}_{2}$-philes" that can optimize the solvent character of $\mathrm{CO}_{2}$ has been suggested. ${ }^{7-9}$ Unfortunately, only few " $\mathrm{CO}_{2}$ philic" polymers exhibit high solubility in $\mathrm{CO}_{2}$, such as fluorinated poly(meth)acrylates, ${ }^{\mathbf{1 0 1 1}}$ perfluoropolyethers ${ }^{\mathbf{1 2}}$ and poly(dimethylsiloxane) (PDMS). ${ }^{\mathbf{1 3 4}}$ These existing polymers cannot meet the growing demand of polymer progress and the pursuit of material cost reduction.

Polyether is $\mathrm{CO}_{2}$-philic due to the nature of the high chain flexibility (glass transition temperature $\left(T_{\mathrm{g}}\right)$ of $\operatorname{poly}(1,2-$ propylene glycol) (PPG) is about $-68{ }^{\circ} \mathrm{C}$ (ref. 15)) and special Lewis acid-Lewis base interactions between the ether oxygen of polyether and the carbon atom of $\mathrm{CO}_{2} \cdot{ }^{16} \mathrm{As}$ " $\mathrm{CO}_{2}$-philic" chain, polyether has already gained considerable attention and was designed for surfactants, ${ }^{17-20}$ and stabilizers ${ }^{21-24}$ in the field of $\mathrm{CO}_{2}$ as solvent and membranes and absorbents for $\mathrm{CO}_{2}$ capture. ${ }^{25-30}$ In order to obtain advanced polyether materials with high $\mathrm{CO}_{2}$-philicity or solubility, efficient polyether

Department of Polymer Science, College of Chemistry, Jilin University, Changchun 130012, China. E-mail: chemjtang@jlu.edu.cn; Fax: +86-431-88498179

$\dagger$ Electronic supplementary information (ESI) available. See DOI: 10.1039/c7ra01587a modification approaches and insight into the thermodynamic parameters affecting the solubility of polyether in $\mathrm{CO}_{2}$ had been studied. Beckman and co-workers ${ }^{31}$ masterly designed ethercarbonate copolymers through incorporating $\mathrm{CO}_{2}$-philic carbonyl group ${ }^{32}$ into a polyether backbone by aluminumcatalyzed copolymerization of cyclic ethers with $\mathrm{CO}_{2}$; the resulting statistical copolymers exhibited extremely high solubility in $\mathrm{CO}_{2}$. Subsequently, Cooper et al. ${ }^{33}$ developed a step growth polymerization route to synthesize the ether-carbonate copolymers and $\mathrm{Wick}^{\mathbf{3 4}}$ further certified the major role of ether-carbonate copolymers- $\mathrm{CO}_{2}$ interactions on the increased solubility of the polymer in $\mathrm{CO}_{2}$ through Gibbs ensemble Monte Carlo simulations. In addition, the introduction of fluorine into the polyether backbone remarkably enhanced the solubility of polyether in $\mathrm{CO}_{2} \cdot{ }^{12}$ Chen and colleagues ${ }^{35}$ further evaluated the key role of intermolecular interactions between (fluorinated) polyether and $\mathrm{CO}_{2}$ by in situ ATR FTIR monitoring system. Polyether solubility can also be enhanced by modifying $\mathrm{CO}_{2}$ phobic hydroxyl end-group into $\mathrm{CO}_{2}$-philic ether, ${ }^{36,37}$ acetate moieties $^{31}$ and trimethylsilyl group. ${ }^{38}$ It is necessary to further develop a versatile polyether modification method for enhancing polyether solubility, and the factors affecting polyether solubility in $\mathrm{CO}_{2}$ need to be further explored.

In this study, we demonstrate an effective approach to enhance polyether solubility in $\mathrm{CO}_{2}$ by incorporating a silicon unit into a polyether backbone and further explored the key factors to increase the solubility of the polymer in $\mathrm{CO}_{2}$. After incorporating silicon unit of $\mathrm{Si}-\mathrm{CH}_{3}$ with low intermolecular forces ${ }^{39}$ into the polyether, the polymer-polymer interactions of the modified polyether should be weaker than that of polyether. 
A

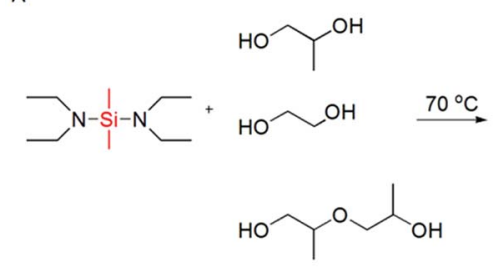

BDEADMS alkyl diol
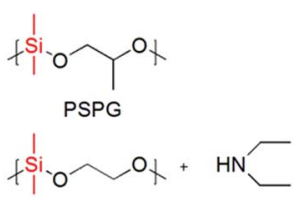
PSEG

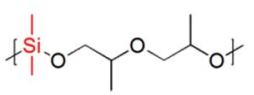

PSDPG

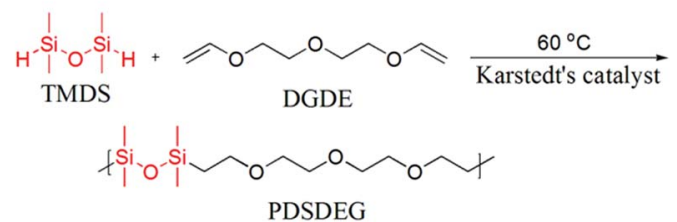

Scheme 1 (A) Condensation polymerization of alkyl diols and BDEADMS. (B) Hydrosilation polymerization of TMDS and DGDE.

PPG was chosen as our model polyether due to its relatively high solubility in $\mathrm{CO}_{2}$ among polyethers. ${ }^{36}$ The structures of designed poly(silyl ether)s are presented in Scheme 1 . Condensation polymerization and hydrosilation polymerization routes were taken to prepare the target polymers and then the phase behavior of target polymers and PPG was studied by cloud point measurements. Surface tension and glass transition temperature tests were implemented to systematically evaluate the key factor to enhance the solubility of polyether in $\mathrm{CO}_{2}$.

\section{Experimental}

\subsection{Materials}

Dichlorodimethylsilane (DCDMS, 99\%), diethylamine (DEA, 99.5\%), propylene oxide (PO, 99.5\%) and poly(ethylene glycol) (PEG, $M_{\mathrm{w}}=2000 \mathrm{~g} \mathrm{~mol}^{-1}$ ) were purchased from J\&K Scientific. Boron fluoride-ethyl ether complex (47-48\% boron fluoride) was obtained from Strem, and 1,2-propanediol (PG, 99.5\%), dipropylene glycol (DPG, 99\%, mixture of isomers), ethylene glycol (EG, 99.8\%), 1,1,3,3-teramethyldisiloxane (TMDS) and platinum(0)-1,3-divinyl-1,1,3,3-tetramethyldisiloxane complex solution in xylene, Pt $\sim 2 \%$ (Karstedt's catalyst) were purchased from Sigma-Aldrich. PG, DPG and EG were thoroughly dried by applying vacuum for 3 hours at $45{ }^{\circ} \mathrm{C}$ before use. Diethylene glycol divinyl ether (DGDE, stabilized with $\mathrm{KOH}, \geq 98 \%$ ) was obtained from TCI. Toluene was purchased from Beijing Chemical Works and freshly distilled before use from a purple $\mathrm{Na}$ /benzophenone ketyl solution. Carbon dioxide $\left(\mathrm{CO}_{2}, 99.95 \%\right)$ was purchased from Changchun Juyang gas industry.

\subsection{Structure characterization}

The nuclear magnetic resonance (NMR) spectra were conducted on a $400 \mathrm{MHz}$ Bruker Avance III NMR spectrometer or a 300 MHz VARIAN NMR spectrometer. Chemical shifts (in ppm) were recorded in $\mathrm{CDCl}_{3}$ list as "residual internal $\mathrm{CHCl}_{3}(\delta=7.26)$ ". The molar masses of the poly(silyl ether)s were detected by gel permeation chromatography (GPC) using a Malvern apparatus equipped with a VE 3580 refractive index detector thermostatcontrolled at $35{ }^{\circ} \mathrm{C}$, a $100 \mu \mathrm{L}$ injection loop and a set of three Malvern columns (T5000, T3000, T1000) thermostat-controlled at $35{ }^{\circ} \mathrm{C}$. Tetrahydrofuran (THF) was used as the eluent at

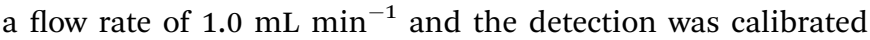
with polystyrene standards of narrow molecular weight distribution. Differential scanning calorimetric measurement (DSC) was performed using a TA instruments Q20 under a nitrogen atmosphere. The samples were heated and cooled at a rate of $10{ }^{\circ} \mathrm{C} \min ^{-1}$.

\subsection{Surface tension measurement}

It had been reported that surface tension $(\gamma)$ is approximately a positive correlation to the cohesive energy density of polymer. ${ }^{5,40}$ In this study, surface tension measurements (Dataphysics OCA20, pendant drop) were used to evaluate the polymer-polymer interactions.

\subsection{Solubility measurements of polymer in $\mathrm{CO}_{2}$}

The solubility was based on cloud point pressure $\left(P_{\text {cloud }}\right)$ that was observed using a high pressure phase equilibrium apparatus composed of a variable-volume view cell (from $40.0 \mathrm{~mL}$ to $85.0 \mathrm{~mL}$ ) with two quartz glass windows and a magnetic stirrer. The temperature of the cell was controlled by a thermostatcontrolled bath and measured by a thermocouple ( $\mathrm{T}$ type, precision of $\pm 0.1^{\circ} \mathrm{C}$ ) inside the cell. The pressure was measured via a pressure transducer (precision of $\pm 0.01 \mathrm{MPa}$ ) equipped with a pressure numerical display. In a typical test, an accurate amount of sample was weighed and placed at the bottom platform of the cell. The cell was sealed and heated to the desired temperature and then flushed four times with $\mathrm{CO}_{2}$ at $0.5 \mathrm{MPa}$ to remove the air. Subsequently $\mathrm{CO}_{2}$ was injected into the cell until the desired pressure was reached using a positive displacement pump (Model SFC-24, SSI, USA). The mass of $\mathrm{CO}_{2}$ was calculated based on the displaced volume, temperature and pressure of the cell with the data of NIST webbook (http://webbook.nist.gov/ chemistry/fluid/). The polymer- $\mathrm{CO}_{2}$ solution was stirred and equilibrated for 30-40 $\mathrm{min}$. The $P_{\text {cloud }}$ was examined by carefully and gradually depressurizing the autoclave and the entire phase transition process was observed and recorded by a camera connected to a computer. The $P_{\text {cloud }}$ was defined as the point at which it was no longer possible to see the syringe needle through the $\mathrm{CO}_{2}$ /polymer mixture, which was because the syringe was behind the view cell; this was the reference. The process was repeated at least three times for each measurement, and an average of the results was taken as the cloud point. For a given polymer, deviations were approximately $\pm 0.5 \mathrm{MPa}$. All the measurements were conducted at $30{ }^{\circ} \mathrm{C}$ unless otherwise noted.

\subsection{Synthesis of poly(propylene glycol) (PPG)}

In order to compare the solubility, poly(propylene glycol) was synthesized as follows. In a typical experiment, the mixture of $15 \mathrm{~mL}$ toluene, EG $(1.24 \mathrm{~g}, 20.0 \mathrm{mmol})$ and boron fluoride ethyl ether complex $(0.52 \mathrm{~mL})$ was stirred for $30 \mathrm{~min}$ at room temperature, and then the solution of $28 \mathrm{~mL}(0.4 \mathrm{~mol})$ of $\mathrm{PO}$ in 
$10 \mathrm{~mL}$ of toluene was added dropwise into the reaction solution over $30 \mathrm{~min}$ in an ice-water bath. The reaction was allowed to proceed for $4 \mathrm{~h}$ and was terminated with aqueous $\mathrm{NaOH}$. The polymer solution was washed three times with pure water, and the organic phase was dried with magnesium sulphate. The solvent was removed under vacuum at $50{ }^{\circ} \mathrm{C}$.

\subsection{Synthesis of bis(diethylamino)dimethylsilane (BDEADMS)}

The synthesis process of bis(diethylamino)dimethylsilane was similar to the previous report. ${ }^{41}$ A solution of dichlorodimethylsilane $(28.40 \mathrm{~g}, 0.22 \mathrm{~mol})$ in toluene $(20 \mathrm{~mL})$ was slowly added dropwise over 1 hour to diethylamine $(69.48 \mathrm{~g}$, $0.95 \mathrm{~mol})$ dissolved in toluene $(400 \mathrm{~mL})$ with ice-water bath cooling and then continued to react for 12 hours at room temperature. The resulting white precipitate was removed via vacuum filtration under $\mathrm{N}_{2}$ atmosphere. Most of the solvent was removed by rotary evaporation at $30{ }^{\circ} \mathrm{C}$, and the crude production was further purified by vacuum distillation twice to yield BDEADMS (31 g, yield 70\%). The product was identified and confirmed by ${ }^{1} \mathrm{H}$ NMR. ${ }^{1} \mathrm{H}$ NMR (400 $\mathrm{MHz}, \mathrm{CDCl}_{3}$ ): $\delta 0.03 \mathrm{ppm}$ $(\mathrm{s}, 6 \mathrm{H}), 0.95 \mathrm{ppm}(\mathrm{t}, 12 \mathrm{H}), 2.79(\mathrm{q}, 8 \mathrm{H})$.

\subsection{Synthesis of poly(silyl ether)s by condensation polymerization}

Poly(dimethylsiloxane-alt-propene glycol) (PSPG), poly (dimethylsiloxane-alt-dipropene glycol) (PSDPG) and poly (dimethylsiloxane-alt-ethylene glycol) (PSEG) were prepared by condensation polymerization of BDEADMS with PG, DPG and EG, respectively. The synthesis route is presented in Scheme 1A. In a typical experiment, PG (0.761 g, $10.00 \mathrm{mmol})$ and BDEADMS (1.928 g, $9.52 \mathrm{mmol}$ ) were charged into a $25 \mathrm{~mL}$ round-bottomed flask equipped with a magnetic stirring bar, a reflux condenser and a vacuum source. The reaction was performed at $70{ }^{\circ} \mathrm{C}$ under reduced pressure $35 \mathrm{kPa}$ for $23 \mathrm{~h}$ and then $5 \mathrm{kPa}$ for $1 \mathrm{~h}$ for the removal of diethylamine, and a colourless or yellowish oily product $(1.103 \mathrm{~g}$, yield $85 \%)$ was thus collected.

\subsection{Synthesis of poly(silyl ether) by hydrosilation polymerization}

Poly(teramethyldisiloxane-alt-diethylene glycol divinyl ether) (PDSDEG) was prepared via hydrosilation polymerization of TMDS and DGDE (Scheme 1B). A typical polymerization reaction was performed in a $25 \mathrm{~mL}$ round reaction flask, which was equipped with a magnetic stirring bar and a reflux condenser. $1.5854 \mathrm{~g}$ (10 mmol) DGDE, $1.3433 \mathrm{~g}$ (10 mmol) TMDS and $10 \mathrm{~mL}$ anhydrous toluene were charged into the reactor and stirred for $10 \mathrm{~min}$, followed by adding three drops of Karstedt's catalyst. Subsequently, the reactant mixture was gradually heated to $60{ }^{\circ} \mathrm{C}$ and stirred for $48 \mathrm{~h}$. The color of the mixture turned from slightly yellow to yellow-brown. After removing toluene by evaporation under reduced pressure, the crude product was redissolved in chloroform for the removal of Karstedt's catalyst by treating the solution with activated charcoal. The product was transferred into Spectra/Por 6 regenerated cellulose dialysis tubing (molecular weight cut-off: $1 \mathrm{kDa}$ ) and dialyzed against ethanol for one day. The finally purified polymer was a colourless or slightly yellowish, viscous fluid (2.1963 g, yield 75\%), and it was characterized by GPC and ${ }^{1} \mathrm{H}$ NMR.

\section{Results and discussion}

\subsection{Preparation of poly(silyl ether)s}

In this study, condensation polymerization and hydrosilation polymerization were used to incorporate silicon unit into the polyether backbone and synthesize a series of poly(silyl ether)s with different molecular weight and repeat unit structures (see Table 1). Microstructure of poly(silyl ether)s can be precisely designed via altering specific comonomers on account of the step growth mechanism. Based on the structure of PPG, PSPG with $50 \mathrm{~mol} \%$ silicon compositions and PSDPG with $33 \mathrm{~mol} \%$ silicon contents were synthesized by BDEADMS with PG and DPG, respectively. Moreover, based on PEG, PSEG and PDSDEG with the same silicon compositions as that of PSPG were synthesized (shown in Scheme 1). The detailed experimental results of synthesized poly(silyl ether)s with different molecular weight and repeat unit structures are listed in Table 1 . The evolution of condensation polymerization of poly(silyl ether)s was monitored by GPC. The kinetic plots of molecular weight versus reaction time of PSPG, PSDPG and PSEG are shown in Fig. 1. The molecular weight of PSPG, PSDPG and PSEG increased until about $1300 \mathrm{~min}$, after which the molecular weight almost no longer increased, and the polydispersity index (PDI, $M_{\mathrm{w}} / M_{\mathrm{n}}$ ) reached the typical value of about 2 for polycondensation. With the same reaction conditions, the final product of PSPG showed a higher molecular weight than PSDPG, which may be attributed to the higher reaction activity of primary hydroxyl group in PG (DPG contains less primary hydroxyl groups due to the type of isomer mixture). The molecular weight of the poly(silyl ether)s could be controlled by adjusting the feed ratio of alkyl diols and BDEADMS. The structure of products was confirmed by ${ }^{1} \mathrm{H}$ NMR spectroscopy (Fig. S1-S3†). PDSDEG was synthesized by hydrosilation polymerization; GPC and ${ }^{1} \mathrm{H}$ NMR spectra (Fig. S4 and S5 $\dagger$ ) of the final purified PDSDEG showed that hydrosilation polymerization is also a good method to modify polyether.

\subsection{Phase behavior of poly(silyl ether)s in $\mathrm{CO}_{2}$}

Analyzing the cloud point curves of poly(silyl ether)s and PPG (see in Fig. 2), we can find that incorporating a silicon unit into either PPG or into PEG decreased their cloud point pressure. For the derivative of PPG, the $P_{\text {cloud }}$ of PSPG-2500 changed in the scope of 9.61 to $16.54 \mathrm{MPa}$ with the concentration range of 0.2 to 1.0 weight percent (wt\%), while the $P_{\text {cloud }}$ of PPG-2000 increased from 18.66 to $24.59 \mathrm{MPa}$ at the concentration of 0.2 to $0.6 \mathrm{wt} \%$. The $P_{\text {cloud }}$ of PSPG-2500 decreased over $9 \mathrm{MPa}$ than that of PPG-2000. The $P_{\text {cloud }}$ of PSPG-5000 was also lower than that of PPG-2000, though the number average molecular weight of PSPG-5000 was over twice that of PPG-2000. PSDPG-2000 exhibited approximately the same cloud point pressures with PSPG-2500, despite the fact that PSDPG-2000 has lower 
Table 1 Experimental results for the physical properties of poly(silyl ether)s and PPG

\begin{tabular}{|c|c|c|c|c|c|c|}
\hline Run & Sample & $M_{\mathrm{n}}\left(\mathrm{g} \mathrm{mol}^{-1}\right)$ & $M_{\mathrm{w}}\left(\mathrm{g} \mathrm{mol}^{-1}\right)$ & PDI & $T_{\mathrm{g}}\left({ }^{\circ} \mathrm{C}\right)$ & $\begin{array}{l}\gamma \\
\pm 0.5\left(\mathrm{mN} \mathrm{m}^{-1}\right)\end{array}$ \\
\hline 1 & PSPG-2500 & 2470 & 3570 & 1.40 & -75 & 22.0 \\
\hline 3 & PSPG-5000 & 5030 & 9250 & 1.84 & -74 & 22.5 \\
\hline 4 & PSDPG-2000 & 1960 & 2890 & 1.50 & -73 & 21.9 \\
\hline 5 & PSDPG-3000 & 3020 & 5350 & 1.77 & n.d. ${ }^{a}$ & 22.7 \\
\hline 8 & PDSDEG-2900 & 2860 & 4840 & 1.69 & -87 & 24.5 \\
\hline 9 & PDSDEG-1900 & 1940 & 2794 & 1.44 & n.d. ${ }^{a}$ & 24.0 \\
\hline 10 & PPG-2000 & 2040 & 2600 & 1.27 & $-68^{b}$ & 30.1 \\
\hline
\end{tabular}

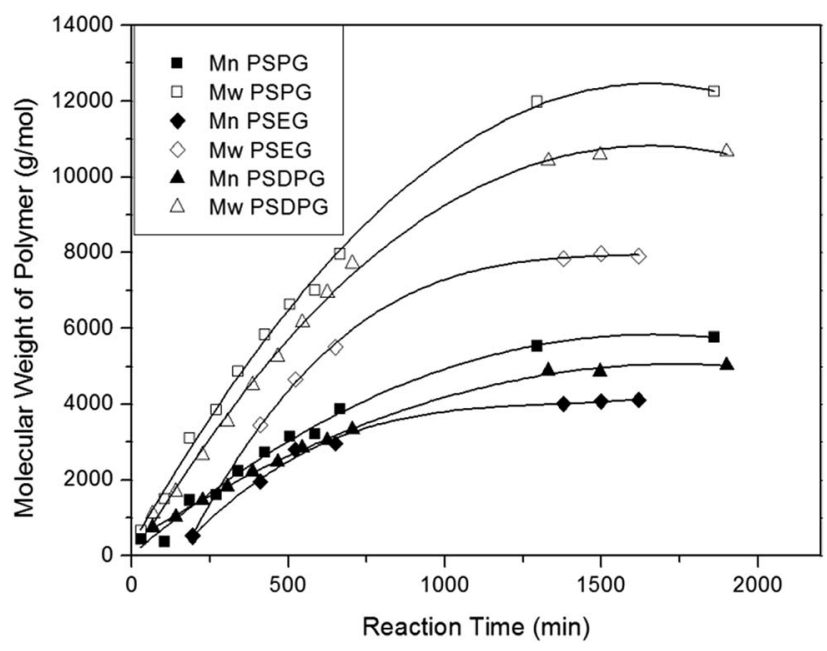

Fig. 1 The kinetic plots of molecular weight versus reaction time of PSPG, PSDPG at $70^{\circ} \mathrm{C}$ and PSEG at $60{ }^{\circ} \mathrm{C}$.

molecular weight. This result indicates that PSPG with more silicon content exhibited higher solubility in $\mathrm{CO}_{2}$ than PSDPG. Clearly, incorporating a silicon unit into PPG significantly enhanced its solubility in $\mathrm{CO}_{2}$. One can also find that poly(silyl ether)s based on PEG exhibited a similar result. PEG with a molecular weight of $2000 \mathrm{~g} \mathrm{~mol}^{-1}$ could not completely dissolve in $\mathrm{CO}_{2}$ at a concentration of $0.4 \mathrm{wt} \%$ and pressure of $30 \mathrm{MPa}$, while the cloud point pressures of PDSDEG-1900 appeared in the 14.8-17.9 MPa range for concentrations of 0.4-1.0 wt\%, and the value of PDSDEG-2900 was also lower than that of PPG. PSEG-4300 exhibited similar phase behaviors with PSPG-5000. Higher pressure was required for PDSDEG-2900 to dissolve in $\mathrm{CO}_{2}$ than that required for PSPG-5000 and PSEG4300; this may be explained from the possibility of two adjacent ethyoxyl units in the PDSDEG backbone causing stronger polymer-polymer interaction, which is unfavorable to the dissolution of PDSDEG. On comparing PSPG-2500 and PSPG5000 with PDSDEG-1900, PSEG-4300 and PDSDEG-2900, we found that the derivatives of PPG showed higher solubility than that of PEG with the same silicon content. Considering the low intermolecular forces between the methyl groups of $\mathrm{Si}-\mathrm{CH}_{3},{ }^{39}$ we speculate that silicon unit contained in poly(silyl ether)s may decrease the polymer-polymer interactions of polyether resulting in higher solubility of poly(silyl ether)s in $\mathrm{CO}_{2}$. This is consistent with the fact that low surface tension and high chain flexibility of PDMS is responsible for its high solubility in $\mathrm{CO}_{2} \cdot{ }^{42}$ In summary, the incorporation of silicon unit both significantly enhanced PPG and PEG solubility in $\mathrm{CO}_{2}$, and poly(silyl ether) based on PPG exhibit higher solubility in $\mathrm{CO}_{2}$ than that based on PEG with the same silicon content.

Considering the excellent solubility of poly(silyl ether)s based on PPG, we further investigated the impact of molecular weight on the solubility of derivatives of PPG (Fig. 3A). It could be seen that PPG exhibited a steeper cloud point curve indicating that the solubility of PPG strongly depends on molecular weight. The $P_{\text {cloud }}$ of PPG increased significantly from 11.9 to 21.3 MPa when the molecular weight increased from 1400 to $2040 \mathrm{~g} \mathrm{~mol}^{-1}$. In contrast, the $P_{\text {cloud }}$ of PSPG increased only from 13.6 MPa to 24.9 MPa with a large increase of molecular weight from 2470 to $8480 \mathrm{~g} \mathrm{~mol}^{-1}$, and the $P_{\text {cloud }}$ of PSDPG

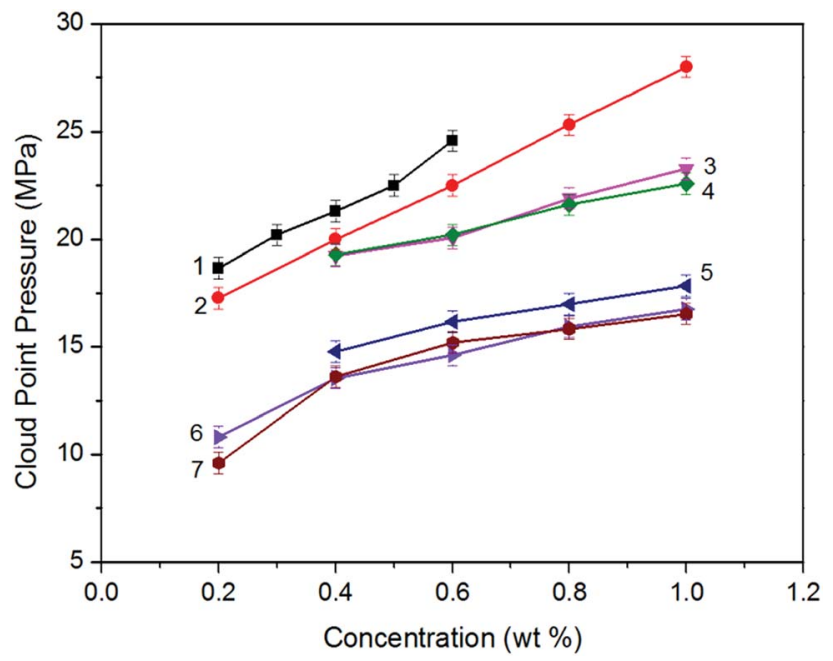

Fig. 2 Phase behavior of mixtures of $\mathrm{CO}_{2}$ with (1) PPG-2000, (2) PDSDEG-2900, (3) PSPG-5000, (4) PSEG-4300, (5) PDSDEG-1900, (6) PSDPG-2000 and (7) PSPG-2500. The cloud point pressure values of all the samples were measured at $30^{\circ} \mathrm{C}$. 

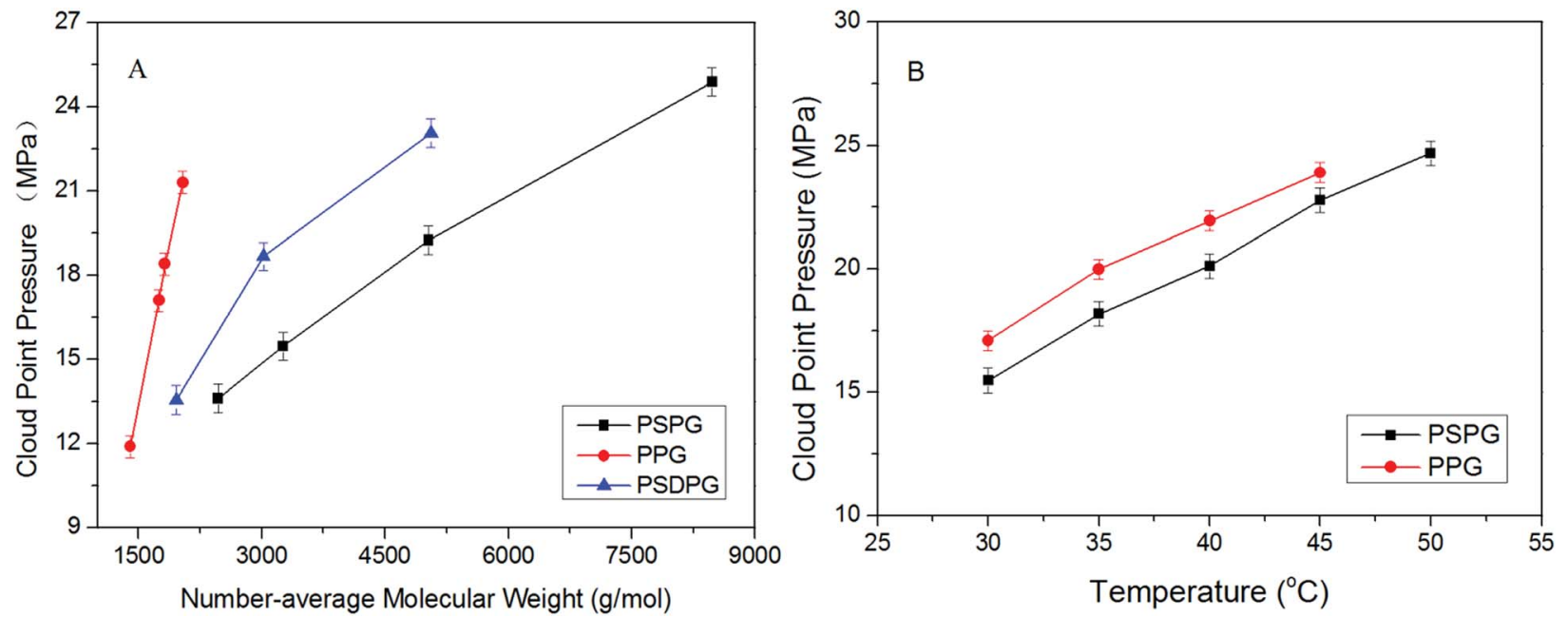

Fig. 3 (A) Molecular weight dependence of the cloud point pressure of PPG, PSPG and PSDPG. The cloud point pressure values of the samples were measured at $30{ }^{\circ} \mathrm{C}$ with the concentration of $0.4 \mathrm{wt} \%$. (B) Temperature dependence of the solubility of PPG-2000 and PSPG-3300 in CO 2 at $0.4 \mathrm{wt} \%$ and $30^{\circ} \mathrm{C}$.

increased slightly from 13.6 MPa to 23.5 MPa with the increase of molecular weight from 1960 to $5060 \mathrm{~g} \mathrm{~mol}^{-1}$. Fig. 3A shows that silicon unit effectively decreased the molecular weight dependence of PPG solubility. We speculate that the strong molecular weight dependence of PPG solubility was attributed to its strong polymer-polymer interactions. Moreover, the high solubility of high molecular weight PDMS with inherently low surface tension in $\mathrm{CO}_{2}$ supports our viewpoint. ${ }^{13}$ This result is especially helpful to the design and utilization of high molecular weight $\mathrm{CO}_{2}$-philic materials. As far as we know, the study aimed to improve polyether solubility in $\mathrm{CO}_{2}$ has mostly focused on low molecular weight PPG $\left(M_{\mathrm{w}} \leq 2000 \mathrm{~g} \mathrm{~mol}^{-1}\right)$ via endgroup modification or side chain functionalization. For high molecular weight polyether, only poly(hexafluoropropylene oxide) $)^{\mathbf{1 2}}$ and ether-carbonate copolymers ${ }^{31}$ exhibited excellent solubility in $\mathrm{CO}_{2}$.

The temperature dependence of the solubility of PPG and PSPG was studied, and the results are shown in Fig. 3B. It was observed that the $P_{\text {cloud }}$ of both PPG and PSPG increased with the rise of temperature resulting from decreased solvability of $\mathrm{CO}_{2}$ toward PPG and PSPG due to the decreased density of $\mathrm{CO}_{2}$ with the rise of temperature. ${ }^{35}$

To get an insight into the phase behavior results of the poly(silyl ether)s, the polymer-polymer interactions were first assessed by surface tension $(\gamma)^{5,40}$ which was measured with the pendant drop experiment (listed in Table 1). Surface tension values decreased from $30.1 \mathrm{mN} \mathrm{m}^{-1}$ at $26^{\circ} \mathrm{C}$ (the reported value of PPG with $2025 \mathrm{~g} \mathrm{~mol}^{-1}$ is $31.5 \mathrm{mN} \mathrm{m}^{-1}$ at $20{ }^{\circ} \mathrm{C}$ (ref. 15)) for pure PPG-2000 to about $22 \mathrm{mN} \mathrm{m}^{-1}$ for PSPG and PSDPG, and the values decreased from $37.5 \mathrm{mN} \mathrm{m}^{-1}$ for PEG $(M=600 \mathrm{~g}$ $\left.\mathrm{mol}^{-1}\right)^{15}$ to about $24 \mathrm{mN} \mathrm{m}^{-1}$ for PDSDEG and to about $22.4 \mathrm{mN}$ $\mathrm{m}^{-1}$ for PSEG-4300. It should be noted that PSPG with different molecular weights have nearly the same surface tension values; this is consistent with the relationship between surface tension and molecular weight, where surface tension changes little when the molecular weight exceeds about $2000-3000 \mathrm{~g} \mathrm{~mol}^{-1} \cdot{ }^{15}$
As expected, silicon unit significantly weakened the polymerpolymer interactions of the polyether resulting from the reduced dispersion force and induction force after incorporating the silicon unit into the polyether backbone. Clearly, the lower surface tension is in favor of the result discussed in this study, which indicates that poly(silyl ether)s exhibit higher solubility in $\mathrm{CO}_{2}$ than PPG. We also noted that the change trend of the surface tension of PSDPG-2000, PSPG-2500, PDSDEG1900 and PPG-2000 (samples with nearby molecular weight avoid the effect of molecular weight on the solubility) was consistent with the trend of solubility, which indicated that higher surface tension resulted in a higher cloud point pressure (Fig. 4). These results proved that polymer-polymer interactions play an important role on the dissolution of polyether in $\mathrm{CO}_{2}$.

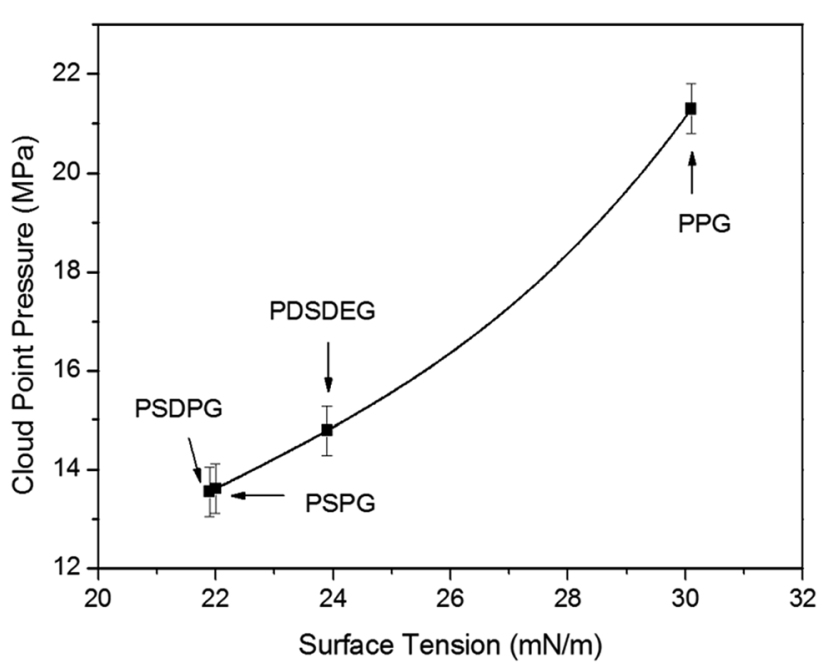

Fig. 4 Relationship between cloud point pressure and surface tension values from PSPG-2500, PSDPG-2000, PDSDEG-1900 and PPG2000. The cloud point pressure values of the samples were measured at $30{ }^{\circ} \mathrm{C}$ with $0.4 \mathrm{wt} \%$ concentration. 
Therefore, the lower solubility of PDSDEG compared to PSPG can be accounted for by the higher surface tension of PDSDEG, and the similar phase behaviors of PSPG-5000 and PSEG-4300 may be explained by the nearby surface tension values.

Furthermore, the relative chain flexibility and free volume were evaluated with $T_{\mathrm{g}}{ }^{36}$ the values of $T_{\mathrm{g}}$, as shown in Table 1 . The $T_{\mathrm{g}}$ of PSEG and PDSDEG decreased to about -88 and $-87^{\circ} \mathrm{C}$, respectively, compared to PEG $\left(T_{\mathrm{g}}=-64{ }^{\circ} \mathrm{C}\right),{ }^{15}$ which stems from the increased free volume and remarkably decreased molecule interactions after incorporating the silicon unit. The lower $T_{\mathrm{g}}$ would improve the entropy of mixing and should be one of the driving forces for PSEG and PDSDEG dissolving in $\mathrm{CO}_{2}$. However, PSEG and PDSDEG appeared to be less soluble in $\mathrm{CO}_{2}$ than PSPG, as discussed previously, though the $T_{\mathrm{g}}$ values of PSEG and PDSDEG were lower than PSPG. Apparently, the improved entropy of mixing is not the main driving force for the enhanced solubility of poly(silyl ether)s in $\mathrm{CO}_{2}$. Polymer- $\mathrm{CO}_{2}$ interactions were then analyzed based on the work of Pauline Vitoux. ${ }^{43}$ The authors had reported the stabilization energy of methoxytrimethylsilane (MTMS) and propyl methyl ether (PME) with $\mathrm{CO}_{2}$ using MP2 method with aug-cc-VDZ basis set where the special functional groups are $\mathrm{Si}-\mathrm{O}-\mathrm{C}$ group and $\mathrm{C}-\mathrm{O}-\mathrm{C}$ group (of $\mathrm{PEG}$ ) respectively. The stabilization energy of $\mathrm{MTMS}-\mathrm{CO}_{2}$ complex $\left(-3.59 \mathrm{kcal} \mathrm{mol}^{-1}\right)$ was slightly higher $\left(0.16 \mathrm{kcal} \mathrm{mol}^{-1}\right)$ than PME- $\mathrm{CO}_{2}$ complex $\left(-3.43 \mathrm{kcal} \mathrm{mol}^{-1}\right)$. Given that the solution of PDMS in $\mathrm{CO}_{2}$ exhibited upper critical solution temperature (UCST) type behavior that stems from weak solute-solvent interactions, ${ }^{44}$ we believe that polyether- $\mathrm{CO}_{2}$ interactions were not significantly changed by the silicon unit and cannot dominate the special phase behavior of poly(silyl ether)s in $\mathrm{CO}_{2}$. These results further confirm that the high solubility of poly(silyl ether)s in $\mathrm{CO}_{2}$ is mainly attributed to lower polymer-polymer interactions.

\section{Conclusions}

In conclusion, a series of poly(silyl ether)s were prepared by condensation polymerization and hydrosilation polymerization. Upon introducing a silicon unit, the cloud point pressure of PEG and PPG was significantly decreased and the molecular weight dependence of PSPG and PSDPG solubility in $\mathrm{CO}_{2}$ compared with PPG was weakened. It should be also mentioned that PSPG with more silicon contents exhibited higher solubility in $\mathrm{CO}_{2}$ than PSDPG. Incorporating a silicon unit into the PEG and PPG backbone is an advisable and convenient approach to enhance their solubility in $\mathrm{CO}_{2}$, and the $\mathrm{CO}_{2}$-philicity of poly(silyl ether) can be altered based on the comonomers. The higher solubility of poly(silyl ether)s in $\mathrm{CO}_{2}$ compared to PPG is mainly attributed to lower polymer-polymer interactions demonstrated by the surface tension measurements and glass transition temperature tests. This study would be conducive to the development of novel functional materials based on polyether, such as surfactants, stabilizers, $\mathrm{CO}_{2}$ adsorbent and $\mathrm{CO}_{2}$-philic polymer membrane.

\section{Acknowledgements}

This research was supported by the National Science Foundation of China (No. 21074042, 50773028), and major science and technology research project of Jilin province (No. 20140203012G X).

\section{References}

1 J. B. McClain, D. E. Betts, D. A. Canelas, E. T. Samulski, J. M. DeSimone, J. D. Londono, H. D. Cochran, G. D. Wignall, D. Chillura-Martino and R. Triolo, Science, 1996, 274, 2049-2052.

2 M. F. Kemmere and T. Meyer, Supercritical Carbon Dioxide in Polymer Reaction Engineering, John Wiley \&VCH, Weinheim, 2005, pp. 1-12.

3 F. K. Christopher and M. A. McHugh, Chem. Rev., 1999, 99, 565-602.

4 E. Girard, T. Tassaing, C. Ladaviere, J. D. Marty and M. Destarac, Macromolecules, 2012, 45, 9674-9681.

5 M. L. O'Neill, Q. Cao, M. Fang, K. P. Johnston, S. P. Wilkinson, C. D. Smith, J. L. Kerschner and S. H. Jureller, Ind. Eng. Chem. Res., 1998, 37, 3067-3079.

6 F. Rindfleisch, T. P. DiNoia and M. A. McHugh, J. Phys. Chem., 1996, 100, 15581-15587.

7 E. J. Beckman, Chem. Commun., 2004, 1885-1888.

8 H. Lee, J. W. Pack, W. X. Wang, K. J. Thurecht and S. M. Howdle, Macromolecules, 2010, 43, 2276-2282.

9 B. Tan, C. L. Bray and A. I. Cooper, Macromolecules, 2009, 42, 7945-7952.

10 J. M. DeSimone, Z. Guan and C. S. Elsbernd, Science, 1992, 257, 945-947.

11 J. B. McClain, D. Londono, J. R. Combes, T. J. Romack, D. A. Canelas, D. E. Betts, G. D. Wignall, E. T. Samulski and J. M. DeSimone, J. Am. Chem. Soc., 1996, 118, 917-918.

12 T. Hoefling, D. Stofesky, M. Reid, E. J. Beckman and R. M. Enick, J. Supercrit. Fluids, 1992, 5, 237-241.

13 Y. Xiong and E. Kiran, Polymer, 1995, 36, 4817-4826.

14 Z. Bayraktar and E. Kiran, J. Appl. Polym. Sci., 2000, 75, 13971403.

15 J. Brandrup, E. H. Immergut and E. A. Grulke, Polymer Handbook, John Wiley \& Sons, New York, 4th edn, 1998, vol. 6, pp. 226-528.

16 S. Kilic, S. Michalik, Y. Wang, J. K. Johnson, R. M. Enick and E. J. Beckman, Macromolecules, 2007, 40, 1332-1341.

17 G. B. Jacobson, C. T. Lee, K. P. Johnston and W. Tumas, J. Am. Chem. Soc., 1999, 121, 11902-11903.

18 G. B. Jacobson, C. T. Lee, S. R. P. da Rocha and K. P. Johnston, J. Org. Chem., 1999, 64, 1207-1210.

19 X. Fan, V. K. Potluri, M. C. McLeod, Y. Wang, J. C. Liu, R. M. Enick, A. D. Hamilton, C. B. Roberts, J. K. Johnson and E. J. Beckman, J. Am. Chem. Soc., 2005, 127, 1175411762.

20 S. R. P. Da Rocha, K. L. Harrison and K. P. Johnston, Langmuir, 1999, 15, 419-428.

21 S. Mawson, M. Z. Yates, M. L. O'Neill and K. P. Johnston, Langmuir, 1997, 13, 1519-1528.

22 D. Bratton, M. Brown and S. M. Howdle, Chem. Commun., 2004, 808-809.

23 D. H. Builes, A. Tercjak and I. Mondragon, Polymer, 2012, 53, 3669-3676. 
24 E. Torino, E. Reverchon and K. P. Johnston, J. Colloid Interface Sci., 2010, 348, 469-478.

25 S. F. Wang, X. Q. Li, H. Wu, Z. Z. Tian, Q. P. Xin, G. W. He, D. D. Peng, S. L. Chen, Y. Yin, Z. Y. Jiang and M. D. Guiver, Energy Environ. Sci., 2016, 9, 1863-1890.

26 M. B. Miller, D. R. Luebke and R. M. Enick, Energy Fuels, 2010, 24, 6214-6219.

27 T. Sakaguchi, F. Katsura, A. Iwase and T. Hashimoto, Polymer, 2014, 55, 1459-1466.

28 S. C. Li, Z. Wang, C. X. Zhang, M. M. Wang, F. Yuan, J. X. Wang and S. C. Wang, J. Membr. Sci., 2013, 436, 121-131. 29 H. Q. Lin and B. D. Freeman, J. Mol. Struct., 2005, 739, 57-74. 30 A. Gonzalez, M. Iriarte, P. J. Iriondo and J. J. Iruin, Polymer, 2003, 44, 7701-7708.

31 T. Sarbu, T. Styranec and E. J. Beckman, Nature, 2000, 405, 165-168.

32 Z. Shen, M. A. McHugh, J. Xu, J. Belardi, S. Kilic, A. Mesiano, S. Bane, C. Karnikas, E. J. Beckman and R. M. Enick, Polymer, 2003, 44, 1491-1498.

33 B. Tan, H. M. Woods, P. Licence, S. M. Howdle and A. I. Cooper, Macromolecules, 2005, 38, 1691-1698.

34 C. D. Wick, J. I. Siepmann and D. N. Theodorou, J. Am. Chem. Soc., 2005, 127, 12338-12342.
35 G. G. Zhou, J. G. Chen, M. X. Wang, M. Zhang, J. L. Guo, S. K. Shen, Z. T. Liu, Z. W. Liu, J. Q. Jiang and J. Lu, Green Chem., 2015, 17, 4489-4498.

36 C. Drohmann and E. J. Beckman, J. Supercrit. Fluids, 2002, 22, 103-110.

37 L. Hong, D. Tapriyal and R. M. Enick, J. Chem. Eng. Data, 2008, 53, 1342-1345.

38 S. Li, Y. Q. Li and J. X. Wang, Fluid Phase Equilib., 2007, 253, 54-60.

39 C. Burger and F.-H. Kreuzer, in Silicon in Polymer Synthesis, ed. H. R. Kricheldorf, Spring-Verlag, Hamburg, 1996, Polysiloxanes and Polymers Containing Siloxane Groups, p. 122.

40 E. Girard, T. Tassaing, S. Camy, J. S. Condoret, J. D. Marty and M. Destarac, J. Am. Chem. Soc., 2012, 134, 11920-11923.

41 M. Padmanaban, M. A. Kakimoto and Y. Imai, J. Polym. Sci., Part A: Polym. Chem., 1990, 28, 2997-3005.

42 E. Girard, T. Tassaing, J. D. Marty and M. Destarac, Chem. Rev., 2016, 116, 4125-4169.

43 P. Vitoux, T. Tassaing, F. Cansell, S. Marre and C. Aymonier, J. Phys. Chem. B, 2009, 113, 897-905.

44 R. Fink, D. Hancu, R. Valentine and E. J. Beckman, J. Phys. Chem. B, 1999, 103, 6441-6444. 